\title{
Evaluation on the Sustainability of Metropolitan Environment for Good Urban Management by Ecological Footprint Model
}

\author{
Farzaneh Sasanpour \& Mohamd Solymani Mehrejani \\ Tarbiat Moallem University, Department of Geography \\ No 43, Moffateh Ave, Tehran Iran \\ E-mail: far20_sasanpour@yahoo.com, M_soleimani_mehr@yahoo.com
}

Received: February 10, 2011

Accepted: May 12, 2011

doi:10.5539/jsd.v4n3p243

\begin{abstract}
Studying the current environmental condition in Iran shows the unsustainability and increasing damage in its ecological atmosphere especially in the biggest human's accomplishment in environment which are cities. Resultant conclusions of the unsustainable development were alarms for environmental policy makers and people involved in preparing a collection of analytic methods and materials for evaluating environmental results and estimating unsustainability level of places. The purpose of this study is to introduce ecological footprint as a new way to evaluate the power of urban environments. Changing a linear and generator city to a circular and dynamic city in which production, consumption and recovering act ideally, is one of ecological evaluation accomplishments. Based on this study, evaluating sustainability power by ecological footprint has been calculated for metropolitan London 5/3, Santiago 2/6 and for Tehran 3/79 per person. This evaluation shows that they have more footprints than world levels ( $2 / 3$ hectare per person) which show unsustainability of metropolitan environment because of the lack of suitable management. So applicable methods, attitudes and reaching evaluable and evident results are known as positive points of the new approach especially in improving urban governance and management.
\end{abstract}

Keywords: Evaluation, Urban Environment, Ecological Footprint, Sustainable development, Urban governance, Urban management

\section{Introduction}

Most of us are living in urban places, where we have forgotten easily that nature is acting in a closed circle, and we don't consider we are encountered with source and facilities restrictions. Metropolitans break natural circles of materials and impose harmful effects on environment but they have the least sensitiveness for maintaining sources and nature. Currently, human being has encountered a new challenge in environmental backgrounds. There is a general agreement about this subject among environmental experts that earth ecosystem, cannot bear current level of economical and consumption activities and their growing trend and cannot be sustainable any more. Because, nowadays there is a double pressure imposed on nature. So imposing human pressures on nature is an affair that has been considered by countries from 1960s, and according to Horst high singer, as world ecologically has extra load, traditional and common economical development model has been weakened and so it is destructive (Arjmandnia,1380,p94). But the fast growth of source consumption with economical growth has increased world gross production $4 \%$ annually. While just $20 \%$ of world population are in absolute welfare and $20 \%$ are in absolute poverty. This gap has been doubled during the past 30 years (Engwicht, 1992, p67). Results of the growth caused jungles destruction, soil erosion, water waste and ecological destruction. So considering evaluation of sustainability in metropolitan environment is a subject that has been noted by experts and urban managers and planners to reach ideal urban management.

\section{Explaining the problem}

The twentieth century can be called rotation and return decade in environment, because, now, communities tend to consider environment, ideal consumption of material and sustainable development rather than fast forward development. Since publishing silent spring written by Rassel Carson in 1942 and occurring some events like accident of tanker trucks and black tides, was an alarm for scientific communities. In his book, while pointing this event in France, England and Belgium beaches, he expresses that life, earth and providing system of human living is going to annihilate in double speed (Carson, 1381, p28, Case and others, 1388,p26). While 20\% of world population has a unique capital, almost $20 \%$ of world population has less than $1 / 4$ percent of global income and they suffer from malnutrition, continuously. This class distinctions along with race and gender, provide problems more than economical problems (Wackernagel and rees,2007,p26). All of established sessions about sustainable development (table 2) and sessions that will be established in future, show ecological knowledge enhancement and human's ideal image of suitable environment of sustainable life. Generally, they are trying to obtain some ways to obtain all their needs with the least damage to their ecological environment. So obtaining some methods that can provide suitable solutions in measuring and evaluating this pressure especially on sustainability of urban 
ecology and moving toward it, is a work that has been noted by experts in some recent decades, to enables them measure damageability level of environment and take a step toward it.

\subsection{Urban environment and its good governance}

Ecological power of cities is a continuous challenge for urban managers and planners, because cities need maintaining large amount of water, energy and raw materials. In addition, urban waste must be taken out of city unless the city will be inhabitable. Thus, for maintaining the city, a steady flow of sources like food, energy and materials must be sent to the city, some of these sources are left in the city, but everything that enters the city, has a footprint. This is a human consumption circle in which all productions change to waste. In the simplest form, this affair can be imagined as a pipe from one side (source side) water enters and from other side waste is absorbed (fig 1). In economical-social metabolism of this trend, nourishing one city is done by its environmental sources. Linear part in the above picture is the ecosystem domain that supports sources flow in a city. This flow passes from using sources, economical production, consumption and absorption of waste (fig 1) (wackernagle, 2003, p21). This figure shows a sustainable city, a sustainable city or a good city means sustainable ecological bases. So, since the main reason of environmental sustainability and making it healthy is improving health and promoting level and quality of citizens' life, evaluating ecological power as the core of environmental studies provides a fundamental base for a good governance and planning of urban environment by preventing and even curing existing crisis. In fact, governance means economical, political and official authority in all country's affair in all territory levels and including tools by which government promotes social alignment and assures people welfare(Midary and others,1383,p35), and here, territory of the city is considered. So, governance problem is the way of managing social affairs in a country or in smaller partition smaller dividions and relation of citizens and governors (Escap, UNDP, ADB, 2007). Finally, urban good governance and management required knowing and evaluating power of urban environment and changing city process to a circular system explained above.

\subsection{Role of evaluation in urban good governance and management}

Evaluation is an important technique for being sure about probable effects of development in environment projects; in fact, it is a tool for environment management and an approach for reducing negative effects of environment. Evaluation is one of the most accepted ways in obtaining sustainable development and sustainability concepts (Shariat \& Monavvari, 1375,p51, Monavvari,1383,p13-14). In fact linkage of environmental considerations in planning and development process as a national necessity might be considered as a guideline-managing action and an approach for obtaining sustainable development of the country (Eftekhari \& Badri 1382, p11, planning and managing organization 1381, p12, Sajedi Almasi, 1380, p105). In this regard, developed evaluating and studying human activities by ecological footprint method provides a content comparison from different aspects of human environment individually. Since development is impossible without good planning, management and governance the more development planning may be more objective and natural, and obtaining its goals for habitable environment is more possible. In fact, evaluation is planning to provide importance of environmental effects, by knowing all environmental, economical, social and cultural dimensions of a society. So, if managers and planners consider environmental considerations in cities' development programs and models from the beginning and compose environmental policies with development plans by evaluation, they can prevent harmful effects. Undoubtedly each kind of investment in maintaining ideal environment and earth source in long time can be economical too (Shariat \& Monavvari, 1375,p7-8). Also knowing evaluating process as a managing tool for developmental managers' provides an opportunity to logical decisions. Not considering evaluation in past years causes ignoring ecological power and imposes pressure on its capabilities and causes many development designs to encounter unsustainability and unsuccessfulness.

\section{Ecological footprint method}

Cities that contain human civilization and activity climax have most portions in effecting environment. After introducing this method by William Rees (regional planner and ecologist) in two decades ago, in 2006 ecological footprint has been calculated $2 / 23$ for each person, in " living planet " report, that is prepared annually for all countries. This means that each person must fulfill all of his/her consumption needs, with considering waste and removing them in mentioned amount of ecological space. Ecological space has been considered 2/4 hectare for each Iranian person, and also ecological footprints of many metropolitans of world have been studied based on this method. In global comparison, footprints of North American countries, 9/4 hectare for each person, is the most. It is four times more than the portion of each person in the world. It means that biophysically increasing substance is limit. Even the current population of world (about $6 / 8$ billion people) cannot expect a lifestyle like Northern Americas' people. Now, if the forecasted population for 2040 is 10 billion, we will encounter a more intense challenge. For fulfilling this need, human will have to use his ecosystem more and more and in fact he is annihilating environment. So, if all people want to have living standard like Northern Americas' people life, we will need 3 earths to be able to fulfill all humans' needs by existing technology (Wackernagle: 2003, p9; Wackernagle and Rees,2007,p63). In recent years, world populations' ecological footprint has been $30 \%$ more than fertile capacity of earth. Comparing sources consumption model in different countries shows that in 2006, ecological footprint of a consumer person in industrial countries, has been 5 times more than a consumer person in poor countries (wwf, 2006, p5, 20). Urban governors and managers should make the subject clear that life 
quality can be improved even if ecological footprint reduces. Real challenges for managers and knowledgeable social groups, are obtaining some ideas for suggesting these facts and real problems in process of sustainable and good environment. So, ecological footprint is an instrument for urban managers in order to help compiling established and long time programs for city habitants. This way, not only causes managers and planners obtain future goals in preventing ecological destructions and inequities, but also they can use environmental fields, educational fields, development evaluation, urban development and sustainable development guidelines to have a good urban environment.

\subsection{Method of calculating ecological footprint}

Approach of footprint analysis is based on this idea that for consuming each kind of products or energies, specified amount of land in one or some environmental domains will be necessary to supply consuming sources and removing their wastes. So, for supplying the whole needed lands for compensating special consumption model, different land uses must be considered. Estimating ecological footprint of a certain population, is a multi steps process which is related to description of source consumption process, wasting and absorbing produced sources (Wackernagle and Rees,2007:65-67). To calculate, at first, we obtain annual consumption of a normal person about a special product by using raw data of that region or country and dividing its whole consumption to population. It's obvious that evaluating this method is so easier than measuring consumptions individually. Many necessary data for introductory measuring can be obtained from country statistical table, like consumption energy, food and jungle production and consumption. Country statistics shows many times both production amounts and consumption amounts, and by using it, commercial balance can be measured.

Commercial balance $=$ production + imports_exports

The next step is estimating needed land for supplying annual capital (aa) to average of that item to production amount or annual output.

$$
\text { Relation number1: aai }=\frac{\boldsymbol{C}_{\boldsymbol{i}}}{\boldsymbol{P}_{\boldsymbol{i}}}
$$

Then total footprint is measured through calculating footprint of an average person per capital footprint of people by evaluating items of his/her shopping basket and also his/her consumption products and services.

$$
\text { Relation number2: }{ }_{i=1 \text { to } n}^{\text {ef }=\sum a_{i}}
$$

And finally, ecological footprint of a particular population (EFp) can be obtained by multiplying average persons' footprint to total population (N):

3: Relation number3: $\mathrm{EF}_{\mathrm{p}}=\mathrm{N}(\mathrm{ef})$

Consumption domains:

In the first step of calculation, based on existing statistics and data, in national, regional and local levels, the annual consumption average of some items in consumption domains: energy, transportation and services, food products, building house and pollution management, will be estimated according to total consumption and population volume (Wackernagel and Rees,2007,p30;Wackearnagle,2003,p4) (table2). After obtaining existing statistics and calculating each one by considering consumption amount and needed land, we should put each obtained digit in EF formula and obtain ecological footprint of each person. After that, by multiplying it by city population or region, footprint of city habitants will be obtained. So, having this calculations, urban managers are able to understand unsustainability of urban environment and then put priorities of action in some necessary parts in first step of their list and can obtain a more sustainable environment by a good urban governance and management and they can solve one of the most important problems of third millennium, reduction of ecological power and resultant urban unsustainability.

\subsection{Evaluation and calculating ecological power of metropolitans (London, Santiago, Tehran)}

Evaluating and calculating through this method not only shows ecological footprint of cities in current conditions, but also it provides a measure for comparison of different kinds of ecological competition in the cities. In sample of calculating ecological footprint of metropolitans 3 metropolitans are compared: London in Europe continent, Santiago in Chile America and Tehran in Iran and Asia continent. Here, resulted general statistics of calculations are studied. Obtained statistics for ecological footprint of London show that its total ecological footprint is $5 / 79$ hectare for each person and this distribution in four categories of human activities related to their needed land is $1 / 61$ in food domain, 1/21 in house domain, 0/92 in transportation domain and 2/05 in product and service domain. Regarding that supporter area of London metropolitan is the whole of England, so calculation of 1998 show that an average person who lives in England, needs more than 5/3 hectare for fulfilling his/her use. While global average use has been 2.4 for each person; also calculations show that ecological footprint of London habitants is a little more than the average of England habitants (Wsp, 2003, 23). These calculations show 8 percent increase in London footprint relative to average footprint of England but this 
increase isn't the same in all groups. For example automobile use in London is considerably less than average of England (4/64\%) because of using public transportation . general ecological footprint of London is defined as footprint of London habitants' consumption plus footprint of extra consumed sources in London for industrial and commercial activities. In fact, these statistics show that the most consumption of London is in product, service and managing waste group. Also comparing statistics of London and England and using relation between these two, it can be said that energy consumption per person in London homes is more than average consumption of England; so, energy footprint in London must be adjust alternately. Waste amount has special importance. London waste is $40 \%$ more than England. Waste amount in its building area and its agricultural waste and mine waste are 36\% and 90\% less than England respectively. And this contradiction is because these activities are done mainly out of London (Wackernagle, 2003, p18-22). This means that London needs a space much more than current space for continuing its life with current consumption mode. Because it is impossible, urban managers and planners can be effective in reaching a sustainable urban environment for London and then England by changing the current way of production and consumption of habitants through using ecological footprint and determining priorities and necessities of act in mentioned domains. Calculations in relation to ecological footprint of Santiago, capital of Chile, are 2/6 hectare for each person, and for Chile it is 2/4 hectare per person. Regarding that Santiago had a population of 4756663 in 1992, total footprint of Santiago in comparison with city area shows that total footprint of Santiago is 16 times more than metropolitan area and 300 times more than built area of Santiago. It means that Santiago habitants need a space 300 times more than the current area with this production and consumption trend. In spite of this fact that the capital has little wood consumption, and other categories (energy and food) consumption in capital city is higher (Wackernagle, 2004.p13-15). Also, based on national statistics of Iran in 1387 ecological footprint of Tehran has been calculated and it is $3 / 79$ for each citizen of Tehran. So, considering Tehran population that is $7 / 5$ million in a 700 $\mathrm{km} 2$ area, it shows that Tehran citizens need a space 388 times more than the current one with this production and consumption trend. In comparison with footprint of an Iranian which is 2.4, Tehran people have footprints 2 times more than other Iran habitants. Finally, unsustainability in Tehran will be transferred to its support area, Iran, which makes it unsustainable too. In general, what are common among these three metropolitans in three different geographical regions are more loads on environment and supportive area and lack of ideal management and planning them. So, as it is obvious, by measuring this method, priority of activities in each basic parts of a metropolitan can be identified for moving toward a sustainable environment and it can help urban managers and planners obtain good urban governance.

\section{Conclusion}

Many different methods have been used in evaluating environmental effects and measuring sustainability of urban regions that have been one-dimensional or are used in special subjects. Ecological footprint, as an instrument for evaluating ecological effects and urban environment power, is a new method that is able to show that economic growth has long time hidden costs and increasing consumption drive cities to unsustainability and ecological disability. Since human economy is defined in a living earth and is dependent on ecological services, the last step of this method is that along with people who use natural products and services, there will be some specified effects on earth but because it can revive itself, there will be no problem till human demands are in recovery capacity of earth. In third millennium, regarding increasing population, expansion of cities and increasing requests, variety and increasing consumption of cities' habitants, cause more pressure on ecological environment and make it more unsustainable. It can be mentioned that in this condition, just urban managers and governors having ecological power and measuring ecological footprint of urban environment and by a systematic and strategic planning, can guide ecological environment and habitant of a city to be sustainable and circular city. Obtaining this management of sustainable sources for cities depends on main necessities and standards of carrying ecological environment and behavior of cities habitants. So, regarding case study, common point in each mentioned metropolitans is that all of them are capital cities. It means that the whole country is the supportive area for supplying food, energy, goods, services and etc. So, this urban unsustainability and linearity of the mentioned capital metropolitans' environment, reaches the country region easily because they are models and in a soon future there will be an unsustainable collection. So by evaluating power of urban environment and having measurements of ecological footprint of each one of metropolitans, urban managers and planners not only can obtain priorities of action in each relative domains but also they can create ideal opportunities for building a sustainable and circular city in relation to good urban management and governance. In healthy and sustainable cities not only there is no extra pressure from biosphere on citizens and habitants but also citizens' behaviors are in a way that ecological capacity can increase considerably. So, by the results of the mentioned method, urban managers can control ecological capacities of cities through controlling waste remove amount and using ecological properties. Also, they must create some communities in cities and supply public supports to reduce human pressure on ecology of city. Without such communities and without proper policy making, it is impossible for managers to be successful in reaching sustainable cities. This study not only proves that ecological footprint in cities can be calculated exactly and clearly, but shows that it is a method for extensive comparing of ecological competition by managers in a city and finally it defines priorities of acts for a healthy urban environment and good urban governance for urbane managers. 


\section{References}

Arjmand nia,Asghar. (1380). ecological footprint, a new approach in evaluation of human effect on environment, in magazine of urban management, number6.

Asafo ajaiee,john. (1381). environment ecology for non economists,translated by Siavash Dehghanian and others, Mashhad, Ferdosi University.

Attari,Siamak. (1381). sustainable development in Green Peace magazine, magazine of jebhe sabz e Iran $2^{\text {nd }}$ year, No 34.

Badri,Ali and Roknodin eftekhari,Abdoreza. (1382). "sustainability evaluation: concept and method", in magazine of geographical research, Ashoora Publishment, Mashhad.

Bahreini,Hossein and Tabibian,Manoochehr. (1377). "model of evaluating quality of urban environment" in magazine of environmental biology, collection of environment research, twenty forth year, environment college, Tehran.

Carson,Rachel. (1971). Silent spring, translated by Abdolhossein Vahabzade, Avaz Koochaki, Amin Alizade, Mashhad, jahad daneshgahi Mashhad University.

Case,Alexander and others. (1379). environment right (first volume) translated by Mohammad Hassan Habibi, Tehran, Tehran university.

Cola,A. (1380). economy of natural sources of e environment and policy making, translated by Siavash Dehghanian and engineer Farrokh Din ghezli, publishment of Mashhad Ferdosi University, First publish.

Engwicht، David. (1992). Toward sustain-cites. Exriro book.

Environment protection organization. (1371). Report of global session of sustainable development special for Rio, Tehran.

Environment protection organization. (1382). Report of global session of sustainable development of Johannesburg (26 august-4 September 2002) Tehran.

Escap. (2007). UNDP,ADB.

Hosein zade Dalir, Karim and Sasanpour,Farzaneh. (1385). ecological sustainability of metropolitan Tehran (ecological footprint method), scientific-research magazine of geographical research, number 83, autumn, Mashhad.

Hossein zade Dalir, Karim. (1380). Methods and Principals of Regional Planning, Samt publishment.

Midari, Ahmad and others. (1383). good governance, development base,Tehran,center of Islamic parliament research.

Monnavarri,Masoud. (1383). guideline of evaluating environment effects of tourism plans, Tehran.

Musa kazemi mohammadi, mehdi musa. (1380). urban sustainable development, concepts and views in geographical research magazine, $15^{\text {th }}$ year,No3.

Organization of management and planning of country. (1381). Technical affair assistance, Technical affair office and compiling criteria, general instruction of evaluating environmental results, civil plans, magazine no 1254 , organization of managing and planning of country, Tehran.

Pears,David w, Jermy j,warford. (1377). non ultimate world, development and environment economy, translated by Dr.Avas Koochaki and others, Ferdosi University of Mashhad, Mashhad.

Rana، S-V.S. (2003). Essentials of Ecology and environmental sciencer NEW Delhi.

Sajedi Almadsi, Hooshang. (1382). necessity of environmental evaluating of programs and plans of urban development, in Abadi magazine, no 293031, Tehran.

Salehi, Esmaiel. (1381). report of global session of sustainable development in monthly magazine of city halls, $4^{\text {th }}$ year, No42.

Sarafi, Mozaffar. (1382). ecological footprint, our basics concepts and guideline in urban management magazine, No12.

Saveen، karan. (2001). instrumental Methods of Environmental Analysis، Delhi.

Shariat, Mahmood and Monavari, Masoud. (1375). An introduction for evaluating environmental effects of environment protection organization, Tehran.

Terner,Ar,K and others. (1381). environment economy, Translated by Siavash Dehghanian and others, Jahad daneshgahi Publishment, Mashhad, First Publish.

Wackernagel ,Mathis and William E. Rees. (2007). Our Ecological Footprint, educing human Impact on the earth.

Wackernagel Mathis \& sahm white Dan Moran. (2002). Using Ecological footprint accounts: from analysis to applications، USA 
Wackernagel، Mathis. (2004). the Ecological Footprint of Santiago DE Chile، Oakland CA USA.

Wackernagle، M. (2003). Thowards a sustainable london: Reducing the capital's Ecological Foot print، WSP Environmental ltd natual strategies LIS London.

Wsp and Natural Strategies. (2003). Toward a Sustainable London, London. Towards Sustainable London.

WWF. (2006). living planet report enter for sustainability studies Switzerland.

Table 1. International sessions and assertions about environment

\begin{tabular}{|l|l|}
\hline Year & Sessions and assertions \\
\hline $\mathbf{1 9 7 2}$ & Report "borders for growth" \\
\hline $\mathbf{1 9 7 2}$ & Stockholm conference about human environment(UN) \\
\hline $\mathbf{1 9 7 9}$ & Bern convention about environment support (UC \\
\hline $\mathbf{1 9 8 0}$ & $\begin{array}{l}\text { Policy of global protection(international union of controlling } \\
\text { nature) }\end{array}$ \\
\hline $\mathbf{1 9 8 0}$ & Protocol of global report of 2000(US) \\
\hline $\mathbf{1 9 8 3}$ & Helsinki protocol about weather quality(UN) \\
\hline $\mathbf{1 9 8 3}$ & Global commission about development and environment(UN) \\
\hline $\mathbf{1 9 8 7}$ & Montreal protocol about reducing substance of ozone(UN) \\
\hline $\mathbf{1 9 8 7}$ & Our common future(Brantland commission for UN) \\
\hline $\mathbf{1 9 9 0}$ & White assertion about urban environment(CE) \\
\hline $\mathbf{1 9 9 2}$ & Our common heritage (England) \\
\hline $\mathbf{2 0 0 2}$ & Earth (South Africa) \\
\hline
\end{tabular}

\begin{tabular}{|l|l|l|l|}
\hline No & Kind of land & usage & Systems \\
\hline 1 & $\begin{array}{l}\text { Land for energy } \\
\text { consumption }\end{array}$ & $\begin{array}{l}\text { Occupied land } \\
\text { through fossil } \\
\text { energy use }\end{array}$ & Land of energy CO2 \\
\hline 2 & $\begin{array}{l}\text { Land for } \\
\text { residency }\end{array}$ & Built environment & Destroyed land \\
\hline 3 & $\begin{array}{l}\text { Existing } \\
\text { consumption } \\
\text { land }\end{array}$ & Agricultural lands & $\begin{array}{l}\text { Pecoverable built } \\
\text { environment }\end{array}$ \\
\hline 4 & Restricted lands & Virgin jungles & $\begin{array}{l}\text { Natural fertile } \\
\text { ecosystems }\end{array}$ \\
\hline 5 & & Non fertile regions & Deserts, ice boards \\
\hline 6 & & & \\
\hline 7 & & & \\
\hline
\end{tabular}

